\title{
SOCIOLOGIA E DIREITO: CONDIÇÕES DE POSSIBILIDADE DO PROJETO INTERDISCIPLINAR
}

\author{
Ricardo Nery Falbo ${ }^{1}$
}

\section{RESUMO}

A exigência interdisciplinar parte do pressuposto de que todo conhecimento científico é limitado e define um movimento duplo e paradoxal. De um lado, a necessidade de dilatar os limites das disciplinas. Nenhuma disciplina pode dizer tudo de seu objeto. De outro lado, a dificuldade de abandonar a especialização. Toda disciplina se constitui e se desenvolve referida ao ideal de unidade do objeto. Do limite da ciência decorre a criação solidária de um conjunto de práticas científicas e de modelos analíticos. A definição dessa criação é compreendida como projeto interdisciplinar. E a sociologia jurídica traduz a realização deste projeto.

Palavras-chave: Interdisciplinaridade - Sociologia jurídica - Direito Sociologia - Ciência

\begin{abstract}
The demand for interdisciplinarity starts from the principle that all scientific knowledge is limited and defines a double and paradoxical phenomenon. Sciences need to go beyond their own bounds. No science can describe its own subject matter. Nevertheless, all science has some difficulty in abandoning specialization. All discipline is referred to the ideal of the unity of their subject matter. It follows from the limits of science the emergence of a series of scientific practices and analytical patterns. The conception of such a creation is considered as interdisciplinary project. And Sociology of Law reflects the implementation of such a project.
\end{abstract}

Keywords: Interdisciplinarity - Sociology of Law - Law - Sociology -Science

\section{Introdução}

1 Doutorado em Sociologia pelo Instituto Universitário de Pesquisas do Rio de Janeiro, Brasil(2004) Professor adjunto da Universidade do Estado do Rio de Janeiro , Brasil 
As reformas dos cursos de direito no Brasil estão historicamente associadas às crises do ensino do direito no País (estrutural, funcional e operacional) (Rodrigues, 2005). O enfrentamento da crise de natureza disciplinar e curricular - que atinge tanto a graduação como a pós-graduação (mestrado e doutorado) - se orienta por disposições normativas que encontram seu fundamento na idéia de interdisciplinaridade e de multidisciplinaridade.

A Resolução CNE/CES no 9/2004 estabeleceu que o objetivo do eixo de formação fundamental é integrar o estudante de graduação em direito no campo e estabelecer as relações do direito com outras áreas do saber. Através da Portaria no 9/2008, a CAPES alterou a configuração original da Tabela das Áreas do Conhecimento - critério de organização das áreas de avaliação da pós-graduação no País - e criou a Grande Área Multidisciplinar e, dentro desta, a área interdisciplinar, dentre outras. Existindo com caráter apenas operacional e função meramente regulamentadora, estas disposições normativas não definem nem a natureza nem as condições de possibilidade de realização do que pode ser chamado de "exigência interdisciplinar no direito".

“Modo de relação entre as práticas científicas especializadas." Esta é a definição de interdisciplinaridade proposta pela revista dos Annales que discute a relação entre história e ciências sociais (Annales, 1989). Resultante de projeto específico de pesquisa, a interdisciplinaridade se caracteriza pela prática de trocas entre os especialistas e pela integração real das disciplinas (Japiassu, 1976). Ela se distingue da multidisciplinaridade e da pluridisciplinaridade pela visão que a orienta quanto à pretensão de superação das fronteiras dos territórios das disciplinas. Aquela evoca justaposição de disciplinas sem cooperação teórico-metodológico entre elas; esta, justaposição de disciplinas com cooperação, mas sem coordenação entre as disciplinas (Japiassu, 1976).

Porém, a interdisciplinaridade é uma prática problemática. A superação das fronteiras das disciplinas nunca é absoluta. A realização desse objetivo não dispensa o recurso a teorias e métodos destas mesmas disciplinas. Assim, toda prática interdisciplinar é considerada como ato de tensão disciplinar (Alvarez-Pereyre, 2003). Esta tensão resulta da diferença de visão que cada disciplina possui sobre seu objeto. Todas as disciplinas realizam a observação e a construção de seus objetos de forma específica. Todas elas descrevem e explicam seus objetos segundo problemas e objetivos igualmente específicos. 
Seus aparelhos conceituais e seus instrumentais técnicos correspondem às diferenças específicas de seus objetos. Assim, toda disciplina é definida à imagem do objeto que ela própria ajuda a constituir. Esta é a hipótese segundo a qual toda disciplina supõe a naturalização de seu objeto. A conseqüência da tradição que assim pensa o objeto é que todo objeto é percebido e concebido como realidade intelectual total, homogênea e única. Daí o ideal de unidade do objeto como preocupação epistemológica e como fundamento das teorias gerais.

$\mathrm{Na}$ base das disposições normativas acima mencionadas há um duplo reconhecimento histórico que não é nada inédito no campo da ciência moderna contemporânea. Primeiro: nenhuma disciplina esgota seu objeto. Segundo: nenhuma disciplina se reduz à outra disciplina. No campo do direito, no entanto, o caráter relativamente inovador tem consistido no questionamento que tais diretrizes têm produzido acerca do direito ensinado e da pesquisa jurídica. O questionamento vem funcionando como condição necessária para a criação e adoção dos novos projetos pedagógicos dos cursos de direito e a renovação dos programas de pós-graduação em direito no País. Porém, a necessidade do trabalho interdisciplinar no campo das ciências sociais e do direito não é definida arbitrariamente de modo racional e abstrato. "Decorre da própria forma de o homem produzir-se enquanto ser social e enquanto sujeito e objeto do conhecimento social." 2

Este trabalho parte do princípio que constitui uma das condições fundamentais da exigência e da necessidade interdisciplinares: a transcendência de visões e de objetos particulares. O problema que daí decorre pode ser resumido nas seguintes questões: Como promover a superação das barreiras disciplinares? Quais são os meios que garantem a realização desta empreitada? Resposta possível a tais perguntas diz respeito à superação dos limites disciplinares tradicionais através da criação de novos campos pretensamente disciplinares e pretensamente autônomos (antropologia jurídica, sociologia jurídica, história do direito).

\footnotetext{
${ }^{2}$ FRIGOTTO, Gaudêncio. "A interdisciplinaridade como necessidade e como problema nas ciências sociais" in JANTSCH, Ari Paulo e BIACHETTI, Lucídio. Interdisciplinaridade; para além da filosofia do sujeito. Petrópolis: Vozes, 1995, pp.26-31.
} 
E a lógica do objeto das novas disciplinas existiria e funcionaria de forma independente da determinação de cada disciplina (antropologia, sociologia, história e direito). Neste caso, a hipótese a ser considerada é a da transdiciplinaridade (AlvarezPereyre, 2003). Outra condição fundamental da interdisciplinaridade é que as disciplinas tradicionais conservem sua própria autonomia. Assim, a prática interdisciplinar - que não seria realizada em termos de aparelhos teóricos e metodológicos - seria considerada como colaboração entre disciplinas que procurariam oferecer umas às outras os esclarecimentos necessários quanto aos limites de seus modelos analíticos. Assim, o historiador esclareceria o sociólogo - e também o jurista - que seus modelos de análise e construções de tipo-ideal não são fenômenos reais, e sim abstrações. O sociólogo poderia contribuir ampliando a perspectiva do historiador - e também do jurista - dando-lhe novos pontos de referência a respeito da interpretação dos fatos históricos - e jurídicos - específicos (Le Goff, 1974).

A hipótese formulada é considerar o caráter paradoxal do projeto interdisciplinar. É mostrar que a necessidade da interdisciplinaridade no direito - que encontra ressonância também em exigências normativas - define também os limites de sua satisfação. O objetivo é mostrar que a idéia de paradoxo elimina a hipótese da interdisciplinaridade como utopia, como projeto que não conhece a existência de território próprio de realização, para definir as condições de possibilidade de sua realização. O problema da interdisciplinaridade não é sua impossibilidade, e sim sua dificuldade prática quanto a condições suficientes e necessárias de sua realização (Alvarez-Pereyre, 2003).

Três são as situações que descrevem a prática da interdisciplinaridade e que podem ser mobilizadas na análise do projeto interdisciplinar no direito. A primeira diz respeito às relações de colaboração possíveis existentes entre direito e outro campo de saber específico (antropologia, história, sociologia); a segunda, à existência de trocas entre as disciplinas que canonicamente definem os diversos ramos do direito e que integram a enciclopédia jurídica; a terceira, à existência de disciplina institucionalmente constituída e considerada como disciplina interdisciplinar (antropologia jurídica, história do direito, sociologia jurídica).

Estas situações de interdisciplinaridade - e principalmente a primeira e a terceira convergem para a mesma situação de tensão no que concerne à superação disciplinar quanto a paradigmas teóricos e metodológicos. São estes marcos que definem a identidade 
das disciplinas (tradicionais e interdisciplinares) através da definição de seus objetos e que permitem ainda compreender as relações entre elas. Eles são a referência na análise do tipo de interdisciplinaridade de que cuida este trabalho - a sociologia jurídica como disciplina ou projeto interdisciplinar.

Do ponto de vista histórico e conceitual, a escolha que aqui é feita implica abordar a constituição da sociologia jurídica quanto aos modos pelos quais ela define seu território e suas relações com as disciplinas tradicionais (sociologia e direito) e das bases sobre as quais bases ela explicita sua razão de ser. Sabendo que a diversidade de critérios corresponde à diversidade de definições e à multiplicidade de objetos, a sociologia jurídica busca seu reconhecimento pela definição que ela oferece dela própria. O problema a ser considerado é se ela é autônoma quanto a seu quadro teórico e procedimentos analíticos e se suas escolhas - e em que termos - são as mesmas escolhas feitas pela sociologia e pelo direito.

O projeto interdisciplinar que aqui é definido como sendo o projeto da sociologia jurídica será analisado de acordo com a preocupação de saber se os modelos teóricos e as técnicas do direito e da sociologia migram para a sociologia jurídica, se os critérios e conceitos operacionais daquelas disciplinas valem também para a nova disciplina enquanto disciplina interdisciplinar, se eles são capazes de explicar os objetos da sociologia jurídica e se a sociologia jurídica se questiona quanto a perguntas desta mesma natureza como exigência ou condição fundamental de sua própria definição como disciplina interdisciplinar.

\section{O problema do direito como objeto das ciências sociais}

A exigência interdisciplinar implica reflexão quanto ao fato de que os objetos das disciplinas são geralmente percebidos e definidos de modo global. Geralmente, o olhar e o discurso dos especialistas estão implicitamente marcados pela idéia segundo a qual seus objetos constituem um todo. No entanto, nenhum objeto existe em si mesmo e para si mesmo. Todo especialista tem um olhar específico sobre seu objeto e persegue um objetivo particular quanto ao mesmo. 
A sociologia e o direito são classificados como ramos das ciências humanas e sociais. Porém, eles se inscrevem no campo destas ciências segundo modos distintos e diversos que não se equivalem nem se assimilam mutuamente. Na pesquisa científica, as diversas ciências humanas e sociais conferem estatutos teóricos próprios à sociedade e ao direito no quadro dos fatos humanos. Porém, estes estatutos teóricos não se confundem com o estatuto que lhes é atribuído no âmbito das relações sociais, dos grupos sociais e das instituições em que a sociedade e o direito existem como expressão de fenômenos quotidianos. Situação ainda diferente decorre da hipótese em que a sociedade e o direito são pensados e vividos no contexto de sociedades que se distinguem histórica, social e culturalmente. Desta forma, "sociedade" e "direito" se distinguem - sem que a distinção promova a ruptura entre eles - quanto à oposição teórica entre objeto teórico e objeto real (Santos, 1993).

Tradicionalmente, o estatuto teórico conferido ao direito no âmbito das ciências humanas e sociais - sociologia, história, direito - é o de mecanismo de controle social que traduz e reflete as necessidades e exigências de determinada sociedade ou grupo social. Especificamente, segundo orientação teórica marxista do direito e do estado, a reflexão sobre o direito "tem constituído o centro da reflexão sobre os modos de dominação e de controle social nas sociedades contemporâneas." 3

Decorrem desta concepção teórica do direito como instrumento de controle social duas perspectivas que orientam de modo diametralmente oposto a investigação do direito no campo das ciências humanas e sociais. A primeira considera o direito como realidade estática que pode ser investigada de forma autônoma e independente em relação à sociedade e à história. Identificado com as leis e códigos vigentes, com o sentido de ordem de conduta humana e com a função de impor padrões de conduta social aos indivíduos, o direito é definido como fato jurídico segundo a distinção entre princípios de causalidade e de imputação (Kelsen, 1998). A segunda considera o direito como realidade a ser investigada no contexto da sociedade em que existe o direito. $\mathrm{O}$ conhecimento do direito dependendo da sociedade com a qual o direito está referido e através da qual o próprio direito existe como fragmento. Assim, por exemplo, as regras do direito penal são a

\footnotetext{
${ }^{3}$ SANTOS, Boaventura de Sousa. O discurso e o poder; ensaio sobre a sociologia da retórica jurídica. Porto Alegre: Fabris, 1988, p. 3.
} 
expressão de semelhanças sociais fundamentais e correspondem à solidariedade social originária destas mesmas semelhanças. $\mathrm{O}$ direito é identificado com as relações sociais e com a solidariedade social e definido como fato social (Durkheim, 1928).

De forma esquemática, a primeira perspectiva corresponderia à investigação do direito no próprio campo do direito e a segunda, a pesquisas conduzidas pela sociologia. Porém, as duas perspectivas contariam com formas teóricas próprias de naturalização de seus objetos com base em práticas reducionistas que definem a unidade e a coerência interna de seus objetos científicos. Estes objetos definem a identidade das disciplinas e são por estas também definidos enquanto territórios em que eles são pesquisados. A definição da natureza dos objetos de estudo - se sociológico ou antropológico, por exemplo depende da comparação em cujo âmbito será possível afirmar se os fenômenos são do mesmo tipo ou não, o que não impedirá o pesquisador de produzir certo tipo de unidade passando por diferentes disciplinas ou objetos (Lévi-Strauss, 1952).

A relação que articula direito e sociedade não tem sido objeto de investigação no campo da prática jurídico-científica tradicional. A definição da identidade do direito e a explicação deste mesmo direito têm acompanhando este quadro negativo de reflexão com respostas distintas e diversas quando se considera a análise do mesmo e único direito. $\mathrm{O}$ direito não é apenas instrumento de controle social. Esta classificação do direito tem por fundamento critério histórico e social de uma época passada que não atende às exigências históricas e sociais da modernidade atual. Esse critério define o direito com o qual o pesquisador se acostuma ou com o qual ele está acostumado. Ele estabelece assim os limites que mantêm o pesquisador afastado do conhecimento do próprio direito. Mesmo considerando o direito como instrumento de controle social, distintas e diversas são as abordagens possíveis na investigação do direito segundo esta definição (sociológica, histórica, política).

Por outro lado, a despeito das diferentes abordagens que pode comportar o estudo do direito como instrumento de controle social, toda pesquisa jurídica se caracteriza pela dimensão semântica da atividade científica que define o sentido do direito. O sentido do direito diz respeito a referentes distintos ou a fenomenologias específicas - o social, o teórico, o doutrinário, o legal, o jurisprudencial (Falbo, 2002). Estes referentes ou fenomenologias são frequentemente reconstruídos no campo jurídico segundo um quadro 
pretensamente teórico que geralmente distingue, opõe e separa as dimensões que existem em relação e que fazem parte do universo fenomenológico que estas dimensões ajudam a definir - o concreto e o abstrato, o particular e o geral, o subjetivo e o objetivo.

A preocupação com a definição do sentido do direito - que define e orienta os diversos tipos de pesquisa jurídica e também o estudo e o ensino do direito - nem sempre questiona as próprias regras da reconstrução dos referentes e das fenomenologias e a própria localização do sentido do direito num dos referentes ou fenomenologias mencionados. Conseqüentemente, os referentes e fenomenologias, e as próprias dimensões que lhe são atribuídas, não são sequer pensadas como fazendo parte de estratégias e escolhas (individuais ou coletivas), não são consideradas como expressão de representações particulares, não são vistas como produzindo exclusões específicas, ainda que tudo isto faça parte do desenvolvimento da atividade cientifica contemporânea.

Por outro lado, a diversidade de resultados que os pesquisadores do direito (juristas e sociólogos) podem apresentar como função da diversidade de dimensões, abordagens ou fenomenologias do direito - ainda que todos ou quase todos continuem usando o vocábulo direito - não esconde a dificuldade quanto ao problema da coerência interna ou unidade do objeto. Nenhuma dimensão, abordagem ou fenomenologia poderia definir e explicar de modo exclusivo e suficiente a coerência do direito como objeto teórico ou como objeto real. Afinal, as relações entre as variáveis (dependentes e independentes) tendem a dissimular o conjunto de tantas outras das relações (Bourdieu, 1979). Além disto, todo objeto de estudo específico - quanto a sua própria imagem ou representação - implica escolhas tão explícitas quanto conscientes referentes a questões teóricas e conceituais, procedimentos metodológicos e analíticos, definição de objetivos. Todo objeto de estudo produz resultados específicos, que decorrem destas mesmas escolhas, e imagens particulares, que correspondem às diversas etapas da atividade científica e que definem a coerência do próprio objeto de modo particular. O problema de todo pesquisador consiste em inscrever cada coerência específica e particular no contexto mais amplo de sua atividade de pesquisa e de sua ciência. Este problema traduz e corresponde a exigências e desafios institucionais e sociais que nem todo pesquisador está disposto ou preparado para enfrentar. 


\section{A sociologia jurídica como problema}

O problema da definição da sociologia jurídica é o problema da definição de seu objeto. Os objetivos da sociologia jurídica são tão distintos como diversos são seus pesquisadores (Timasheff, 1937/1938). Este é o mesmo problema enfrentado pela sociologia urbana. De modo específico, ela não tem nem objeto teórico nem objeto real (Castells, 1975). Do ponto de vista histórico, o surgimento da sociologia do direito (Gurvitch, 1960) se confunde com o aparecimento da sociologia geral (Giddens, 2004). A história das duas disciplinas parece seguir o desenvolvimento do pensamento sociológico com a contribuição de Durkheim, Marx e Weber. O direito como símbolo visível da solidariedade social (Durkheim, 1928), o direito como instrumento da classe dominante (Marx/Engels, 1962) e o direito como tipo ideal de dominação legítima (Weber, 1995) são temas atribuídos e reivindicados pelos primeiros teóricos tanto da sociologia como da sociologia do direito. Seguindo o percurso inaugural atribuído de forma comum às referidas disciplinas, não é possível identificar se - e em que momento - as relações entre direito e sociedade passaram a ser objeto de preocupação e reflexão explícitas quanto a desafios teóricos e metodológicos capazes de promover a distinção entre sociologia e sociologia do direito e a conseqüente separação das mesmas disciplinas em campos autônomos de conhecimento científico. A indistinção quanto à originalidade na demarcação do território destas duas sociologias inviabiliza o questionamento quanto à antecedência da prática da pesquisa científica em relação à emergência da sociologia e da sociologia do direito. Não é possível tampouco explicar de forma distinta a institucionalização das duas disciplinas como momento histórico inaugural. A distinção quanto aos rótulos que lhe são atribuídos não constitui condição suficiente no enfrentamento do problema da definição e distinção de seus objetos específicos de predileção. Os campos programáticos que escolhem seus objetos e que rejeitam outros tantos objetos permanecem indeterminados. A hierarquia de suas prioridades de 
investigação continua desconhecida. Sua definição com base em elementos internos próprios ou em relação a outras áreas do conhecimento permanece ignorada. ${ }^{4}$

Este quadro negativo referido ao momento histórico inaugural das duas disciplinas bastaria para negar a existência da sociologia jurídica como disciplina autônoma e inscrevê-la no quadro da sociologia tout court. Seria a hipótese de afirmar a preocupação dos fundadores da sociologia com o direito enquanto objeto de estudo. Apenas quanto a isto é que eles poderiam ser considerados "sociólogos do direito" ou fazendo "sociologia jurídica". A contrapartida de sociólogos preocupados com o direito corresponderia à hipótese do estudo do direito realizado por juristas com preocupação sociológica. Léon Duguit, Emmanuel Lévy, Maurice Hauriou, Henri Lévy-Bruhl e Jean Carbonnier fazem parte da categoria dos assim chamados juristas-sociólogos, que, no entanto, nunca deixaram de ser teóricos do direito (Gurvitch, 1960). Uma vez que a hipótese da sociologia jurídica como disciplina interdisciplinar, com o mesmo estatuto tradicional das disciplinas tradicionais, depende de objeto de estudo específico, de critérios precisos de ordem teórica e de regras metodológicas definidas, não seria possível afirmar sua existência. Ela existiria como parte da sociologia, que, assim, permaneceria intacta. Ela estudaria o direito de tipo particular e em situação social específica e experimentaria a necessidade de inventar métodos novos para objetos que continuariam pertencendo às disciplinas tradicionais. Seu interesse por tais objetos - quanto às formas e sentidos de manifestação do direito e às relações que articulam direito e sociedade, direito e cultura, direito e política - não descaracterizaria a atividade da competência da sociologia e do direito.

Por outro lado, se a sociologia jurídica não existe como nova disciplina ou disciplina especial, de forma independente do estatuto tradicional de cientificidade do conhecimento (objeto, teoria e método), é possível afirmar sua existência como modelo de reflexão e prática intelectuais que articulam a relação entre sociedade e direito (Junqueira, 1993). Esta forma de pensar a sociologia jurídica define uma das condições necessárias de todo trabalho de reflexão sobre a prática interdisciplinar - o problema da especialização que caracteriza as disciplinas científicas tradicionais. Ainda que a comunidade científica

4 Estas discussões foram feitas por Paulo Condorcet quanto à caracterização da disciplina Introdução ao Estudo do Direito no livro A Introdução ao Estudo do Direito no Pensamento de Seus Expositores, da livraria Liber Juris (1982). 
lhe negue o reconhecimento de disciplina científica autônoma ou de disciplina de fronteira, as instituições de pesquisa e de ensino do direito no Brasil e no mundo lhe reconhecem existência formal como disciplina ao lado das demais disciplinas. Ela não teria nascido se a sociologia e o direito não tivessem sido historicamente constituídas de modo reducionista ou não se revelassem limitadas quanto a seus objetos de investigação. De alguma forma, a história e a evolução das disciplinas tradicionais em questão - na medida em que estas disciplinas traduzem os modos pelos quais o pensamento científico se constitui no nível institucional - explicam o nascimento da sociologia jurídica. Como a institucionalização e o desenvolvimento da sociologia e do direito se orientaram pelo processo de especialização da ciência moderna, elas perderam ou não mais produziram a compreensão dos fatos e acontecimentos que marcaram o século XX e que ainda marcam o século XXI. É possível ainda afirmar que a emergência e o desenvolvimento da sociologia jurídica respondem a exigências de revisão crítica contínua e continuada da visão e do conhecimento científicos. As mudanças verificadas em seu campo traduzem movimento paralelo que parece refletir as transformações pelas quais passam as ciências sociais e humanas ainda no século XXI.

Ao representar esforço explícito de lidar com as relações entre direito e sociedade e de produzir reflexão nova como corolário da especialização e do reducionismo do conhecimento científico tradicional - ainda que mantendo relação teórico-metodológica com as disciplinas tracionais que vivem a crise da ciência moderna -, ela atende a exigências de conhecimento novo que respondem a demandas que se originam em diversos setores e segmentos da sociedade. A realização desta condição autoriza a inscrição da sociologia jurídica de forma legítima no campo da interdisciplinaridade. Outro critério na explicação da emergência da sociologia jurídica como interdisciplina é a relação que ela estabelece entre direito e sociedade, direito e cultura, direito e política, direito e economia, a despeito das diferenças de abordagem teórica (o direito como reflexo da sociedade estudada ou o direito como elemento dinâmico desta sociedade, por exemplo).

Outras condições da análise da interdisciplinaridade da sociologia jurídica que escapam os limitem deste trabalho, e que permitiriam afirmar, diminuir ou negar a singularidade desta disciplina e, assim, reforçar as ligações entre as disciplinas cardeais (tradicionais) e de fronteira (disciplinas novas de caráter interdisciplinar), são as 
seguintes $^{5}$ : a) conhecer as bases sobre as quais são definidas sua identidade e sua razão de ser; b) reconhecer a existência de etapas na sua evolução histórica; c) distinguir suas pesquisas quanto a objetos mais antigos e mais recentes; d) definir se seus objetos históricos - inaugurais e originais, em parte ou no todo - são ou foram também objetos da sociologia e do direito; e) questionar, quanto a seus objetos, os métodos e teorias empregados; f) saber se suas pesquisas produziram inovação técnica específica ou se conheceram apenas a transposição de ferramentas já existentes em campos vizinhos ou se houve a extrapolação de um campo para outro; g) saber se as etapas de seu trabalho científico mudaram ou continuam as mesmas; h) definir que relações ela estabelece com as demais disciplinas; i) saber se ela realizou produção teórica de aparelho conceitual capaz de explicar as mais diversas formulações pluridisciplinares ou se ela recorreu à transcendência das problemáticas disciplinares para constituir seu edifício científico e assim considerar o desafio científico que representa o continuum dos fatos humanos; $\mathrm{j}$ ) verificar se ela seguiu o mesmo itinerário que a sociologia e o direito; k) analisar se a base de dados com a qual ela é confrontada é a mesma base de dados da sociologia e do direito; 1) se ela se surgiu e se desenvolveu em campo específico e se esta tendência tem tendido a diminuir; m) saber qual é o aspecto essencial que ela privilegia em seu âmbito; n) saber se é a especificidade real ou a especificidade relativa que mais caracteriza seus objetos; o) saber se seus desafios teóricos e metodológicos fazem com que, em seu interior, surjam divergências talvez mais essenciais do que as diferenças de configuração na base dos objetos.

\section{Sociologia, Direito e Interdisciplinaridade}

Da definição de interdisciplinaridade proposta pelos Annales decorrem três conseqüências básicas. Primeira: as relações entre as ciências fundamentam o trabalho interdisciplinar. Segunda: as relações entre as práticas científicas especializadas permitem questionar a identidade das ciências e saber o que a definição de uma diz da outra.

\footnotetext{
${ }^{5}$ A especificação destas condições levou em conta a análise da empreitada interdisciplinar entre a etnolinguística e a etnomusicologia realizada por Frank Alvarez-Pereyre em L'exigence interdisciplinaire.
} 
Terceira: as relações práticas entre as ciências importam a ruptura com o dogmatismo e o positivismo.

Essa definição permite ainda pensar os meios e as vantagens da colaboração entre as disciplinas (Delamarre, 1986). Quanto aos meios: a) utilização recíproca e cruzada dos mesmos dados; b) comunicação dos fichários dos informantes; c) coordenação com os pesquisadores de outras disciplinas no avanço de cada pesquisa; d) difusão e discussão dos relatórios; e) reuniões coletivas. Quanto às vantagens: a) a pesquisa interdisciplinar constitui contexto privilegiado para a formação do pesquisador; b) ela contribui para formar o olhar sobre o outro, conduzindo a considerações mais reais sobre si mesmo; c) ela é verdadeiro laboratório permanente para métodos e técnicas de trabalho.

Nos termos dos Annales, a interdisciplinaridade da sociologia jurídica definiria a instabilidade das fronteiras dos territórios da sociologia e do direito, rejeitaria as definições abstratas destas disciplinas e reivindicaria a realidade sociológica e institucional das mesmas em referência à análise dos processos de tradução e de apropriação conceituais e metodológicas. A análise histórica e as concepções teóricas dos objetos constituem critérios que ajudam na explicação do surgimento e da identidade destas disciplinas. No entanto, o problema consiste em saber se a sociologia e o direito apresentam suas dúvidas e incertezas nesse tipo de relação e se elas revelam preocupação com a redefinição de seus projetos e práticas. Afinal, essa relação entre as práticas científicas têm traduzido confronto disciplinar revelador de duas tendências contraditórias: ou o confronto procura distinguir as disciplinas ou o confronto procura destacar as semelhanças entre elas. O problema destas tendências consiste em saber se o confronto das disciplinas - que revela a importância dos objetos e dos critérios na definição das mesmas - tem promovido a discussão da centralidade das questões teórico-metodológicas destas mesmas disciplinas. Esta é uma das condições da realização de pesquisas e trabalhos que pretendam sua inscrição no campo interdisciplinar. E a prática interdisciplinar, nos termos dos Annales, supõe que aquilo que pertence à sociologia e ao direito venha a integrar o campo da sociologia jurídica. Porém, esta passagem depende do questionamento explícito acerca da concepção de mundo e da organização deste mesmo mundo e da estruturação específica de configuração social e jurídica particular. 
Pesquisas e trabalhos existem que se inscrevem no campo do trabalho interdisciplinar, que mostram a interdisciplinaridade como necessidade ou exigência reconhecida e que recomendam a interdisciplaridade na abordagem dos dados e nos títulos das disciplinas. No entanto, tanto na área do direito como na área da sociologia, é preciso saber qual é o interesse revelado quanto à avaliação das práticas interdisciplinares. Daí a importância da observação de pesquisas, trabalhos e disciplinas para trazer à baila os desafios de todo projeto interdisciplinar. Daí o problema das denominações e definiçõos, das relações entre os objetos e a linguagem, e do momento da análise, com referência à articulação das partes constitutivas dos objetos e da relação entre as disciplinas.

Como disciplina de fronteira e quanto às suas condições de existência, a sociologia jurídica tem conhecido prática corrente. Seus critérios são tão distintos e diversos como distintos e diversos têm sido seus objetivos e objetos, seus quadros teóricos e seus procedimentos analíticos. O problema é saber se a sociologia jurídica, a despeito de variação segundo a época e a escola, se define por referência a algum critério que possa ser considerado como sendo suficiente. Deste critério decorreria visão limitada do objeto e representação típica da atividade científica tradicional. Daí a necessidade de explicitação dos critérios que definem a sociologia jurídica e de saber se - e como - tais critérios produzem a classificação de seus objetos. A análise dos critérios permite ainda conhecer o momento histórico e o modo pelo qual a sociologia e o direito se separaram, bem como se esta separação ocorrera por meio de algum tipo oposição e qual o sentido desta oposição.

Especificamente, é possível reconhecer a separação entre direito e sociologia do direito segundo oposição entre prescrição jurídica (“determinação jurídica em uma lei ou um código") e norma jurídica (“determinação jurídica transformada em ação") (Erhlich, 1986) oposição essa que corresponde à oposição histórica entre o que é tradicional e o que é moderno no mundo germânico. Esta oposição invoca distanciamento histórico e social em relação ao objeto dominante da ciência do direito (a prescrição jurídica), que se orienta tradicionalmente pela concepção positivista de tipo kelseniano.

Aquela perspectiva invoca ainda a historicidade da ordem interna das associações sociais e a dinamicidade do caráter quotidiano e rotineiro de suas normas, revela a especificidade do direito de forma (relativamente) independente do estado e da coação estatal, interpela a divisão do trabalho científico instaurada no século XIX, instaura 
métodos de investigação da sociologia do direito que migram da história do direito e da sociologia. Esse questionamento da divisão tradicional do trabalho científico, que tem por fundamento a oposição entre direito estatal e direito extra-estatal, entre prescrição jurídica e norma jurídica, pode estar referido à construção teórica de outro tipo e assim explicar a interdisciplinaridade segundo objetos distintos. A oposição entre direito social e direito estatal pode estar referida à lógica, ao desenvolvimento e à crise do mundo capitalista contemporâneo, corresponder ao problema do pluralismo jurídico e ensejar o uso de modelos teóricos e de métodos de investigação tanto da sociologia como da antropologia (Santos, 1988). O tema da "ordem" pode aproximar tanto a sociologia jurídica de Santos como a de Erhlich da preocupação tradicional que possui a ciência do direito. Porém, este se afasta da teoria jurídica tradicional pela visão histórica do direito; aquele, pelo sentido do direito como relação que articula discurso e poder. Porém, em relação a Santos, Erhlich revela ainda concepção tradicional do direito, considerado como fenômeno normativo.

\section{Conclusão}

É possível afirmar que a sociologia jurídica tenha surgido como reação à tradição intelectual que ainda caracteriza o ensino do direito e a pesquisa jurídica no século XXI. Esta tradição corresponde à tendência que o direito possui de viver a heterogeneidade como verdadeiro pesadelo científico e à tentação de afirmar a pureza como ideal científico. Por outro lado, a diversidade de critérios na explicação da existência da sociologia jurídica poderia semear a dúvida quanto a dois diagnósticos distintos que caracterizam a interdisciplinaridade como projeto paradoxal: o da espontaneidade da tentação com a pureza e o da simples preocupação com a revisão das etapas de seu desenvolvimento histórico.

A sociologia jurídica como projeto interdisciplinar se caracteriza pelo fato de rejeitar os limites considerados excessivamente restritivos da sociologia e do direito e de buscar a superação destes mesmos limites. A explicação que ela oferece de si mesma como discurso interdisciplinar é constituída através do confronto de critérios constitutivos de seus objetos de estudo. De natureza distinta, estes critérios deveriam ser situados historicamente em momentos diferentes quanto a perspectivas referentes a objetos particulares. Do ponto de vista histórico, a ausência de articulação e de hierarquização 
destes critérios pela sociologia jurídica resulta na equiparação ou equivalência dos mesmos. Esta crítica vale também para a ausência de historicidade quanto à variedade das opções metodológicas. Paradoxalmente, este fato constitui ameaça ao próprio projeto interdisciplinar representado pela sociologia jurídica.

Se a complexidade constitutiva do objeto deve representar o centro das preocupações da sociologia jurídica, ela não tem excluído do projeto interdisciplinar que representa esta disciplina a preocupação lógica com a unidade do objeto enquanto categoria-chave da interdisciplinaridade. Nisto consiste o paradoxo que define seu projeto interdisciplinar: a preocupação com a unidade do objeto - ainda que espontânea e implícita - parece privar o objeto de sua complexidade constitutiva.

\section{Referências Bibliográficas}

ALVAREZ-PEREYRE, Frank. L'exigence interdisciplinaire: une pédagogie de l'interdisciplinarité en linguistique, ethnologie et ethnomusicologie. France : Éditions de la Maison des sciences de l’homme, 2003, pp. 07-11.

ANNALES. Número 6. Paris: Armand Colin, 1989, p. 1322.

BOURDIEU, Pierre. La distinction; critique sociale du jugement. Paris: Minuit, 1979,pp 113-117.

CASTELLS, Manuel. "O que é a Sociologia Urbana" in CASTELLS, Manuel. Problemas de Sociologia Urbana. Portugal: Editorial Presença; Brasil: Martins Fontes, 1975, pp. 2352.

DELAMARRE, Marie Jean-Bruhnes. L'Aubrac, étude ethnologique, linguistique, agronomique et économique d'un établissement humain, t. Vii. Paris : Cnrs, 1986, pp. 0919.

DURKHEIM, Emilio. La división del trabajo social. Madrid: Daniel Jorro, 1928, pp. 5781, 123-129.

ERHLICH, Eugen. Fundamentos da Sociologia do Direito. Brasília: Unb, 1986, p. 36. 
FALBO, Ricardo Nery. Natureza do conhecimento jurídico; generalidade e especificidade no direito da criança e do adolescente. Porto Alegre: Fabris, 2002, pp. 09-12, 141-186.

FERREIRA, Paulo Condorcet Barbosa. A introdução ao estudo do direito no pensamento de seus expositores; material para uma bibliografia brasileira da disciplina. Rio de Janeiro: Liber Juris, 1982.

FRIGOTTO, Gaudêncio. "A interdisciplinaridade como necessidade e como problema nas ciências sociais" in JANTSCH, Ari Paulo e BIACHETTI, Lucídio. Interdisciplinaridade; para além da filosofia do sujeito. Petrópolis: Vozes, 1995.

GIDDENS, Anthony. “O que é a Sociologia?” in GIDDENS, Anthony. Sociologia. Lisboa: Fundação Calouste Gulbenkian, 2004, pp. 03-19.

GURVITHC, Georges. "Problèmes de Sociologie du Droit" in GURVITCH, Georges. Traité de Sociologie, vol. 2, Paris : Puf, 1960, pp. 177-188.

JAPIASSU, Hilton. Interdisciplinaridade e patologia do saber. Rio de Janeiro: Imago, 1976, pp. 72-74.

JUNQUEIRA, Eliane Botelho. A Sociologia do Direito no Brasil. Rio de Janeiro: Lumen Juris, 1993, pp. 09-16.

KELSEN, Hans. Teoria Pura do Direito. São Paulo: Martins Fontes, 1998, pp. 79-113.

LE GOFF, Jacques. "Les mentalités - une histoire ambiguë » in LE GOFF, Jacques e NORA, Pierre. Faire de 1'histoire. France : Gallimard, 1974, pp. 76-90.

LÉVI-STRAUS, Claude. Antropologia estrutural. Rio de Janeiro : Tempo Brasileiro, 1985, p.41.

MARX, Karl, \& ENGELS, Friedrich. Le manifeste communiste. Paris: Union Générale d'Éditions, 1962, p. 30.

RODRIGUES, Horácio Wanderlei. Pensando o ensino do direito no século XXI: diretrizes curriculares, projeto pedagógico e outras questões pertinentes. Florianópolis: Fundação Boiteux, 2005, pp. 25-60. 
SANTOS, Boaventura de Sousa. O discurso e o poder; ensaio sobre a sociologia da retórica jurídica. Porto Alegre: Fabris, 1988, pp. 64-78.

Introdução a uma ciência pós-moderna. Porto: Edições Afrontamento, 1993, pp. $33-49$.

TIMASHEFF, N.S. "What is 'Sociology of Law'?” in The American Journal of Sociology, XLIII, july-1937/may-1938.

WEBER, Max. Metodologia das Ciências Sociais, parte 2. São Paulo: Cortez; Campinas: Unicamp, 1995, pp. 349-359. 